\title{
Article
}

\section{Structuring Roles and Gender Identities within Families Explaining Suicidal Behaviour in South India}

Lasrado, Reena, Chantler, Khatidja, Jasani, Rubina and Young, Alys Available at http://clok.uclan.ac.uk/13329/

Lasrado, Reena, Chantler, Khatidja ORCID: 0000-0001-9129-2560, Jasani, Rubina and Young, Alys (2016) Structuring Roles and Gender Identities within Families Explaining Suicidal Behaviour in South India. Crisis: The Journal of Crisis Intervention and Suicide Prevention, 37 . pp. 205-211. ISSN 0227-5910

It is advisable to refer to the publisher's version if you intend to cite from the work. http://dx.doi.org/10.1027/0227-5910/a000379

For more information about UCLan's research in this area go to http://www.uclan.ac.uk/researchgroups/ and search for < name of research Group>.

For information about Research generally at UCLan please go to http://www.uclan.ac.uk/research/

All outputs in CLoK are protected by Intellectual Property Rights law, including Copyright law. Copyright, IPR and Moral Rights for the works on this site are retained by the individual authors and/or other copyright owners. Terms and conditions for use of this material are defined in the policies page.

\section{CLoK}

Central Lancashire online Knowledge www.clok.uclan.ac.uk

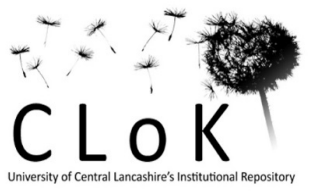



in South India

--Manuscript Draft--

\begin{tabular}{|c|c|}
\hline Manuscript Number: & CRI-MS-1994R1 \\
\hline Full Title: & $\begin{array}{l}\text { Structuring Roles and Gender Identities within Families Explaining Suicidal Behaviour } \\
\text { in South India }\end{array}$ \\
\hline Article Type: & Research Trends \\
\hline Corresponding Author: & $\begin{array}{l}\text { Reena Lasrado } \\
\text { The University of Manchester } \\
\text { Manchester, UNITED KINGDOM }\end{array}$ \\
\hline Corresponding Author's Institution: & The University of Manchester \\
\hline \multicolumn{2}{|l|}{$\begin{array}{l}\text { Corresponding Author's Secondary } \\
\text { Institution: }\end{array}$} \\
\hline First Author: & Reena Lasrado \\
\hline \multicolumn{2}{|l|}{ First Author Secondary Information: } \\
\hline \multirow[t]{2}{*}{ Order of Authors: } & Reena Lasrado \\
\hline & Khatidja Chantler, PhD \\
\hline Author Comments: & $\begin{array}{l}\text { The findings discussed in this manuscript is part of a larger study that explored the } \\
\text { cultural and structural mechanisms of suicide in India. The manuscript identifies a gap } \\
\text { in perception and comprehension of risk factors which need to be positioned within the } \\
\text { context of social and cultural process. This has potential to inform prevention and } \\
\text { intervention programs in India and worldwide. }\end{array}$ \\
\hline
\end{tabular}




\begin{tabular}{|c|c|}
\hline \multirow[t]{3}{*}{ Suggested Reviewers: } & $\begin{array}{l}\text { Erminia Colucci, PhD } \\
\text { The University of Melbourne } \\
\text { ecolucci@unimelb.edu.au }\end{array}$ \\
\hline & $\begin{array}{l}\text { China Mills, PhD } \\
\text { Lecturer, The University of Sheffield } \\
\text { china.mills@sheffield.ac.uk }\end{array}$ \\
\hline & $\begin{array}{l}\text { Fatemeh Rabiee-Khan, PhD } \\
\text { Professor, Birmingham City University } \\
\text { Fatemeh.Rabiee@bcu.ac.uk }\end{array}$ \\
\hline \multicolumn{2}{|l|}{ Opposed Reviewers: } \\
\hline Response to Reviewers: & $\begin{array}{l}\text { Reviewer \#1: } \\
\text { 1.Page 4, paragraph } 1 \text { and line 4: We have included references for both thematic } \\
\text { analysis and Bourdieu's theoretical concepts. We have also provided a foot note to } \\
\text { explain Doxa. } \\
\text { 2.Page } 4 \text {, paragraph } 2 \text { and line } 1 \text { : We have revised the sentence to prevent repetition } \\
\text { and replaced the first author's full name with initials as suggested. } \\
\text { 3.Page } 4 \text {, paragraph } 2 \text { and line } 8 \text { : We have deleted the brackets. } \\
\text { 4.Page5, paragraph } 2 \text { and line } 6: \text { We have added quotations from the survivors group, } \\
\text { traditional healers -Page } 5, \text { paragraph } 3 \text { and line } 9 \text { and mental health professionals - } \\
\text { Page } 6, \text { paragraph } 1 \text { line } 5 \text { to support the theme under discussion. } \\
\text { 5.Page } 8 \text {, paragraph } 2 \text { and line } 6 \text { : The sentence has been revised and split into two } \\
\text { 6.Page } 11 \text {, paragraph } 2 \text { and line } 9 \text { : References are included from more recent } \\
\text { literature on the topic of suicide and menstruation } \\
\text { 7.We have reworded and restructured the sentences in the first paragraph of the } \\
\text { discussion section on page } 11 \text { and } 12 \text { to make the argument clearer. } \\
\text { 8.We considered reviewer's suggestion and deleted the brackets along with its content } \\
\text { in conclusion section to avoid repetition. } \\
\text { Reviewer \#2: } \\
\text { 1.A short description is added towards the end of the first paragraph on page } 1 \\
\text { explaining what is meant by 'structuring roles' in this study. } \\
\text { 2.A brief section on limitations is included on page } 14, \text { paragraph } 2 \text {. This } \\
\text { acknowledges the challenges associated with transferability of study findings. } \\
\text { 3.The manuscript has been proof read to check for any typographical and grammatical } \\
\text { errors. }\end{array}$ \\
\hline
\end{tabular}




\section{Structuring Roles and Gender Identities within Families Explaining Suicidal Behaviour in South India}

\section{Introduction}

Understanding risk factors for suicide is not just an actuarial process, but it is also about exploring the life process that leads to such decisions and actions. This paper analyses how a series of life events and everyday situations lead men and women to attempt suicide while examining the interactions of culture, structure, gender and constantly structuring roles as both antecedents and explanations of suicidal intent and behaviour. Structuring roles in this paper refers to the process of constant changes between agency and structure in the formation and structure of an individual's roles within families and society. The structure dictates a set of dispositions which has the power to generate and influence perceptions and practices of the present and the future (Bourdieu, 1994).

The vast majority of existing literature concerning suicide in India has tended to focus on epidemiology and risk factors (Vijaykumar, 2007). Very limited attention has been given to understanding the influence culture plays (Colucci et al., 2013). In India suicidal behaviour receives biomedical attention rather than psychosocial interventions (Adityanjee, 1986; Rao, 1978; Vijaykumar, 2007). The National Crime Records Bureau in India records statistics in relation to deaths through suicide, however no records are kept in cases of attempted suicide. According to their recent reports (NCRB, 2014) nearly 43\% of suicides for the year 2013 were attributed to reasons such as family problems and illness but they fail to define or explain what constitutes family problems and how they might lead to suicides.

The epidemiological studies indicate a wide variety of reasons associated with completed suicides such as economic hardships including in rural, agricultural areas, relationship problems, farmer suicides, student suicides, caste discrimination, military suicides, 
alcoholism, depression, mental and physical illness (Manoranjitham et al., 2010; Maselko and Patel, 2008; Milner et al., 2013; Nath et al., 2012; Radhakrishnan and Andrade, 2012; Vijayakumar, 2007; Patel, 2007; Patel, 2005). Most of these studies have used quantitative methods emphasising statistical analysis, that are useful in helping to illuminate risk factors but do not offer an in-depth exploration into risk factors from the perspectives of survivors. These data predominantly provide epidemiological findings and reports from medico-legal autopsies. Very few studies have used qualitative methods to explore life situations of individuals who have experienced attempting suicide and few have sought to situate suicide within a cultural explanatory model. The relevance of using qualitative methodologies is evidenced, for example, in Staple's (2012b) ethnographic study of suicides in a leprosy colony of Bangalore. He recognised how social situations and cultural beliefs shared within the region posed a risk of suicide for young healthy men with parents affected by leprosy, who held high aspirations but lacked opportunities and resources.

In line with the NCRB report (National Crime Records Bureau, 2012), the independent survey by Patel and colleagues (Patel et al., 2012) highlighted that male rates of suicide were higher than female rates in India, however the overall rates for both male $(26.3$ per 100,000$)$ and female $(17.5$ per 100,000$)$ in the independent study were higher than those recorded by the NCRB. This led to the conclusion that the national records underestimate male suicide rates by $25 \%$ and female rates by $36 \%$. It has been widely reported that the NCRB rates underestimate the true rates of suicide (Vijayakumar et al., 2005; Manoranjitham et al., 2007). The reasons for this underestimation are thought to relate to the stigma and shame that families may face if the cause of death is reported as suicide. Equally the illegality of suicide in India also leads to many cases of suicide getting misreported as accidental death. The variation in male and female suicde rates calls for a better understanding of gender dynamics from the perspectives of survivors and those who treat survivors of attempted suicide. 
The overall aim of this study was to explore the cultural implications of attempted suicide and its prevention in South India. The study aimed to achieve this by exploring the experiences of survivors of attempted suicide and perspectives of mental health professionals and traditional healers. However, in this paper we focus specifically on cultural dynamics within the context of family with specific reference to the cultural process and gendered notions that have implications for suicidal behaviour.

\section{Methods}

In-depth interviews were conducted with survivors of attempted suicide (Male $=6$, Female $=$ 9), mental health professionals $(\mathrm{MH})(\mathrm{n}=8)$ and traditional healers $(\mathrm{TH})(\mathrm{n}=8)$ in a range of urban, semi urban and rural locations including Bangalore, Mysore and Kodagu districts in Karnataka, Southern India. Interviews took place within the settings of a hospital/ clinic/ temple/ church/ office or home. The survivors were sampled purposively, within the age group of 18-44years, and inclusive of any gender, religion, caste and class, regardless of schooling level, means of livelihood and professional background. The sample was accessed through mental health professionals who acted as gatekeepers. The mental health professional participants were recruited purposively and included psychiatrists (2), general practitioners (1), psychologists (2) and social workers (3). The healers were sampled from Hindu (3), Muslim (3) and Christian (2) religions, using a snow ball method, with the help of previous users of healing services, believers of services and personal contacts from across the Karnataka region in South India. It was important that participants understood and spoke either English or Kannada to facilitate the interviewing process and obtain rich data. The researcher RL is fluent in both. Informed consent was obtained from participants in writing or audio recorded in case of illiterate participants. 


\footnotetext{
${ }^{1}$ Doxa refers to a deep system of beliefs that are naturalised through the process of unconscious mechanism where individuals accept and practice many things without even knowing them as though they were legitimate (Bourdieu, 2000; Bourdieu and Eagleton, 1994).
} 
Cultural prescriptions towards gender-based roles within the structure of family were a key focus in all three sets of data. In particular, the influence of gender assigned roles in causing distress and suicidal behaviour became repeatedly evident through the course of analysing participants' accounts.

The survivor participants' accounts revealed that the duality and polarisation of cultural practices subjected them to internalize cultural norms and made day-to-day living with set boundaries challenging, distressing and gradually contributing to suicidal behaviour. For instance, there were many examples of women survivors describing situations within their roles as a wife, mother and daughter, in which they felt forced to continue in the marriage, for the good of children or to preserve parents' reputation. "My mother got me married, I didn't want her name to be spoilt. I was young, I didn't understand things" (S 14). These compromises often included being abused. Abuse included examples of domestic violence, sexual abuse, physical abuse, sexual jealousy, neglect and encouraging another individual to inflict torture on the victim.

In the healers and mental health professionals' accounts, gender roles and influences were also apparent in their explanations of clients' attempted suicide. However, these were presented largely in terms of stressors. Furthermore the definition and interpretation of what was a gender-related or role-related stressor usually reflected their own socio-cultural, religious, economic, educational and professional background. For example, healers associated most of the reasons with religious aspects such as lack of faith, ill effects of magic, spells, 'Rahu kala' ('bad times') and evil effects on women during menstruation. They also indicated that conflicts within families are a result of 'western influence' which guide men and women to adopt new cultures and cultural behaviours. 'Our land is called a land of toil (karma bhumi). There is a system in the society, especially the family system which we have inherited from our ancestors. However, the younger generation hardly follow these ..... They 
are driven by the 'foreign culture' (referred to as a land of pleasure), creating more desires which can't be fulfilled' (Field notes -TH 7). Mental health professionals associated suicidal events with depression and other mental health conditions. They explained challenges and frustrations experienced by their clients as a result of gender and family structures as precipitators of the presenting mental states. “....family members have complaints and the expectations are higher than what can be achieved, this leads to increased levels of stress and women are victimised into abuse and torture most of the time" (MH 1). Both healers and professionals focused primarily on the immediate events that preceded the attempt.

\section{Abuse, Violence and torture within set boundaries}

The participants from all three groups discussed intimate partner and family member violence as the most common form of violence that affected survivors' physical, mental, emotional and psychological wellbeing. Conflicts within families were a significant precursor of attempted suicide as also identified in epidemiological studies. A deeper understanding of participants' accounts revealed that an individual's gender role within a family had an influence on their behaviours and interactions with other members of the family. For example certain roles within the family structure (father, son-in-law, son, and mother-in-law) come with power through tradition and are often associated with responsibility. Most of the participants highlighted the cultural tradition of assumed roles and responsibilities that various members within a family share which is said to have assigned them with power. As in the case presented by one of the mental health professionals in the following extract, the mother and the brother-in-law of the survivor who was under treatment, felt it was their responsibility to get her married in order to secure her future even if this was against her wish. 
"Her father passed away mother was managing the family and her brother-in-law was taking care of the family needs, her mother forced her to get married to another guy who was well off, they tortured her and got her married. Family abuse, in this case particularly mostly sister's husband, uncles, mamas (mother's brothers), they take right over the family, they have asked them to listen to them" (MH 5)

The survivor participants' accounts revealed instances of repeated violence perpetrated by their husband, parents-in-law and other members of the extended family. One of the survivors explained that although she and her husband lived separately from her parents inlaw, their interference and influence was persistent which impacted her relationship with her husband and resulted in more violence and abuse.

The data depict the exercise of power by taking on particular roles within the family. There is a constant interaction between the structural settings, which define an individual's position and orient perceptions and behaviours. For example, husbands and in-laws hold power and utilise this by control and domination demonstrating the interplay of power in this process through symbolic and physical violence where women (daughters-in-law) are subjected to violence. The findings revealed that gender and age were instrumental in determining who held power in the family. However, cultural capital (practices, norms, traditions) opened up margins for manoeuvring field (family, community, society) and agency (status-educated, employed) that could be used to redistribute power according to assigned cultural roles. As Bourdieu (1999: 123-129) explains "power over social or physical space/field comes from possessing various kinds of capital, takes the form in appropriated physical space." For instance, despite being educated and employed, female survivors translated their social position as a wife and daughter in-law into being subjects of social and cultural domination, which in turn left them with less power. However, there is a dichotomy where the position of the mother in-law is in spatial opposition and is substantiated with cultural domination and 
power. These oppositions are asserted in a social space of family with symbolic distinctions of cultural capital assigning power. With this understanding of how culturally assigned roles share power and responsibility we now move on to explain how it varied for men and women that transformed everyday situations to stressful events leading to attempted suicide .

\section{Men and Suicide}

The distressing nature of cultural expectations are clearly expressed through survivors' accounts where male participants expressed how their identity of being a man, husband and son was linked to economic responsibilities and professional success. One of the male survivors was particularly distressed when he felt that his power and authority in the family was threatened when his wife took over the responsibility due to his failure to earn money and look after the family. The participants from the mental health professional's group added to this by expressing that culturally it is unmanly for a man to express his emotions or cry and share his feelings. This notion of masculinity leaves men with fewer options for support in the family and in society. A similar finding was evident in Staples (2012a) ethnographic study where healthy young men from a leprosy colony in Bangalore felt distressed when they failed to fulfil their responsibilities and lacked opportunities for employment. Healer participants expressed that stress among men and women is caused due to the changes in life style, a desire for more wealth and unending demands of wives upon their husbands which contribute to men attempting suicide.

Gender differences were particularly distressing for one of the survivors who was transgender and gay. His situation worsened when no one in his family, school, community or friends understood him. Instead, he was beaten up by his family for cross dressing and mocked in his school. Although there was a history of transgenderism in previous generations of the family, it did not seem culturally appropriate to talk about this in the family or in public. 
Most survivors experienced stress and internal conflicts because of cultural expectations towards their roles as a husband, son and a father. The interplay of power in exercising each role was dynamic and was influenced by cultural practices and social norms. Roles as a husband, son, father are imbued with power that are based on practices, gender and what is happening in the field of family, this was challenging for survivor participants.

\section{Women and suicide}

For women survivors there was a constant struggle and conflict with self and their surroundings to reach the high expectations of being a perfect daughter, wife, daughter in-law and mother. The vast majority of survivor interviews contained accounts of abuse, assault and torture within marriage and those involved in heterosexual relationships outside marriage. Marriage is a significant institution in Indian society (Milner Jr, 1994). Culturally, there is a strong emphasis on marriage and it is seen as women's responsibility to make a successful marriage. There were also accounts from women who were under a lot of pressure from the family to continue in an abusive marriage as leaving it would affect the family reputation. Participants from all three groups acknowledged the dominant stereotype that impact on women and their parental family. This extension of damage to reputation is directed particularly to the mother of the bride as the community are likely to berate her for conflicts within marriage and/or broken marriages. This therefore functions as an additional layer of pressure to keep women in abusive or otherwise unsatisfactory relationships. In addition, life as a single woman in India is difficult:

'I feel I can live a peaceful life only if I leave him, but my mother and neighbours say that it is difficult to live without a husband.' (Survivor 11)

In the case of women survivors who were brought up by a single parent (mother), they had been persuaded not to split away from their husband because their mother did not want the 
daughter to face the hardships of a single woman. There was an implicit reference here to the ways in which community and society categorises women to be of loose character, shameless and disrespectful when they break away from marriage and live as singletons. In the context of women survivors who were in premarital sexual relationships, they encountered a lot of pressure to marry the person with whom they were involved to justify their act of sexual involvement. Marriage is seen as legitimising sexual relations and offering protection against victimisation or ill-treatment within the community.

Being surrounded with this pressure, participants insisted on marriage regardless of whether or not they loved the man they had had a sexual relationship with. The cultural binding and different standards for sexual behaviour based on gender explains why women feel culturally bound to marry the person with whom they are sexually involved despite abuse, torture and misuse, and when they fail to marry this may lead to attempted suicide. On the other hand, men's reputations are not usually tarnished for their sexual relationships in comparison to women as indicated by the participants during the interviews. A few of the healers in connection with relationships questioned 'why are girls held accountable for involving in a relationship or being seen with a man?' (TH 2). They questioned the social and cultural norms that discriminate between men and women and perpetuate double standards.

'He has spoiled (sexually exploited) me. I can't leave it at this; I shall live or die with him alone. I cannot marry anybody else and neither do I wish to.' (Survivor 2)

Participants discussed that it was important for women to be married by a certain age to avoid being stigmatised in the community. Unmarried women were particularly affected by stress and desperation when their family failed to find the right partner for her to marry as this was critical in avoiding stigma and could lead to suicidal behaviour. It is implicit in the data that a woman gains her identity and status through a man (father/husband/son) in Indian culture. 
Professionals and healers acknowledged the issue of stigma that forces women to suffer in silence and when faced with sufferings beyond their ability to cope result in attempted suicide. A few of the male Muslim healers were unsympathetic of women who were in premarital or extra marital relationships and they blamed women for their sexual involvement and problems in relationship. While a woman professional also blamed women for conflicts in the family stating that 'women have reduced tolerance and coping abilities in modern days' (MH 4). It brings to light how participants' own religious and cultural backgrounds influenced the way they perceived risk factors and treated their clients.

Among other reasons, healers (Muslim and Hindu) indicated that occurrence of suicide among women were high during menstruation. They believed that women are more susceptible to the effects of bad omens during this period. They were of the opinion that women are generally weaker than men which is the reason for the higher number of suicides among women than men - but this is contradicted by the evidence from suicide surveys (NCRB, 2014; Patel et al., 2012). The Christian healers did not draw any relation between the higher rates of suicide among women and menstruation. Professionals discussed menstruation and suicide on the basis of hormonal changes indicating possibilities of depression and low moods. There is a wide body of literature which discuss the association between suicide and menstruation from a biomedical perspective (Brockington, 2001; Leenaars et al., 2009; Saunders and Hawton, 2006; Afzali et al., 2012; Tasto and Insel, 2013).

\section{Discussion}

The gender identity of men being men, and women being women, within the boundaries of cultural prescriptions, laid a heavy burden of morality upon women survivors, whilst at the same time men were reported to have the cultural power to regulate or deregulate female behaviour. The social standards which attach morality to a woman's conduct and behaviour 
are a result of cultural capital. However these social standards for behaviour are questioned through the process of on-going interactions between agency (education, financial independence, career- woman) and social setting/field. Skeggs' (1997) concept of 'frameworks of representations and values' are appropriate in understanding a number of women survivors in this study. These women materialised cultural capital, power and practices, which in turn produced structures within families and society to recognise a woman as a mother, daughter, professional, wife and daughter in-law with her own identity and set of values. This was possible when a woman's agency, social, cultural and economic capital interacted with family and social structures. It is these frameworks that establish what it is to be a woman and not just a woman with "cultural baggage" as described by Skeggs (1997).

The evidence of social and cultural domination is exposed through the accounts of some of the healers who were under the influence of doxa. They for example, perceived women during menstruation as inauspicious, affected by a bad omen, emotional, weak and prone to suicidal thoughts. In this way healers were involved in what Spivak (1988) calls ideological reproduction through the misreading of Holy (Hindu) Scriptures that legitimised their perception of women as sexually 'subaltern' subjects, inauspicious and prone to the effects of bad omens. However, some healers also recognised physical and emotional frailty during menstruation and its relevance to suicidal behaviour. Although healers' perceptions were dominated by cultural and religious capital they recognised physical and mental health conditions from biomedical perspectives as well.

On the other side of the debate of women's identity are the women survivors' experiences of premarital relationships, physical and symbolic violence expressed in terms of fear, resentment, humiliation, perceived and actual loss of power and being treated as an object of pleasure. In this context women survivors attempted to persuade men to marry them with the aim of preserving honour, cultural capital and re-establishing themselves within a social field. 
However, failure to achieve the desired outcome resulted in adopting a suicidal habitus. Attempted suicide, in this case, is used not only as a means of persuasion but as a measure to safeguard and politicise a woman's identity and rights in order to influence her movement through social space. The act of attempting suicide to politicise women's identity and rights is a way of demonstrating symbolic capital.

Framing gender identity for men is interpreted in terms of masculinity through the symbolisms of cultural institutions and practices that define power, authority, independence and sexuality. Cultural representation of masculinity was an important aspect in the lives of male survivors. They expressed distress about being unemployed, having to wait upon parents for consent to marry, lack of power and not being able to control their environment as a sign of diminishing social positioning which led to them perceiving themselves as 'being a loser, failure and a loner'. Butler recognises 'being a man and being a woman are internally unstable affairs. They are set with ambivalence precisely because there is a cost in every identification, the loss of some other set of identifications, the forcible approximation of a norm one never chooses, a norm that chooses us but which we occupy, reverse, re-signify to the extent that the norm fails to determine us completely" (Butler, 1993: 126). The enforcing nature of doxa, cultural prescriptions for behaviours, appearance and dressing based on gender was particularly distressing for a survivor who was transgender, but also for other survivors. Society failed to empathise with the survivor and exercised symbolic violence by excluding him from respectable social positioning, limiting opportunities for career advances and making it impossible to engage in a relationship. This was distressing for the survivor who struggled to understand and accept the cultural norms and the harassment sanctioned by cultural power.

\section{Conclusion}


In conclusion this study has shown how crucial it is to recognise the role of cultural capital and power in understanding survivors' experiences within the context of family and suicidal dispositions. It further analyses the influence of cultural beliefs and doxaic norms upon service providers' approaches to treating suicidal behaviour. The study clarifies that it is not in identifying specific risk factors but in exploring the socio-cultural process that affects social, emotional, physical and mental wellbeing that bears the potential to explain suicidal behaviours and plan appropriate interventions.

As a qualitative study, the aims are not generalizability but transferability. Transferability refers to the ability of a study's findings to speak to and resonate with other similar contexts (Lincoln and Guba, 2000). We do not claim that the transferability of this study would include those people who died by suicide. 


\section{References}

Adityanjee D. (1986) Suicide Attempts and Suicides in India. International Journal of Social Psychiatry 32: 64-73.

Afzali S, Taheri SK, Jamilian M, et al. (2012) The Relationship between Menstrual Cycle Phases and Suicide Attempts in Suicidal Women Admitted to the Poisoning Ward of Farshchian Hospital, Hamedan, Iran. Iranian Journal of Toxicology 5: 531-534.

Aronson J. (1995) A pragmatic view of thematic analysis. The qualitative report 2: 1-3.

Bourdieu P. (1994) Structures, habitus, power: Basis for a theory of symbolic power. Culture/power/history: A reader in contemporary social theory: 155-199.

Bourdieu P. (1996) Understanding. Theory, Culture \& Society 13: 17-37.

Bourdieu P. (1999) The weight of the world: Social suffering in contemporary society, California: Stanford University Press.

Bourdieu P. (2000) Pascalian meditations, California: Stanford University Press.

Braun V and Clarke V. (2006) Using thematic analysis in psychology. Qualitative research in psychology 3: 77-101.

Brockington I. (2001) Suicide in women. International Clinical Psychopharmacology 16: S7-S19.

Butler J. (1993) Bodies that matter : on the discursive limits of "sex", New York: Routledge.

Colucci E, Lester D, Hjelmeland $\mathrm{H}$, et al. (2013) Suicide and culture: Understanding the context: Hogrefe.

Corbin J and Strauss A. (1942) Basics of qualitative research. 3rd ed. Thousand Oaks, California: Sage Publications.

Leenaars AA, Dogra TD, Girdhar S, et al. (2009) Menstruation and Suicide A Histopathological Study. Crisis-the Journal of Crisis Intervention and Suicide Prevention 30: 202-207.

Lincoln YS and Guba EG. (2000) The only generalization is: There is no generalization. Case study method: 27-44.

Manoranjitham S, Charles H, Saravanan B, et al. (2007) Perceptions about suicide: A qualitative study from southern India. National Medical Journal of India 20: 176-179.

Manoranjitham SD, Rajkumar AP, Thangadurai P, et al. (2010) Risk factors for suicide in rural south India. British Journal of Psychiatry 196: 26-30.

Maselko J and Patel V. (2008) Why women attempt suicide: the role of mental illness and social disadvantage in a community cohort study in India. Journal of Epidemiology and Community Health 62: 817-822.

Milner A, Sveticic J and De Leo D. (2013) Suicide in the absence of mental disorder? A review of psychological autopsy studies across countries. International Journal of Social Psychiatry 59: 545-554.

Milner Jr M. (1994) Status and Sacredness: A General Theory of Status Relations and an Analysis of Indian Culture: Oxford University Press.

Nath Y, Paris J, Thombs B, et al. (2012) Prevalence and social determinants of suicidal behaviours among college youth in India. International Journal of Social Psychiatry 58: 393-399.

National Crime Records Bureau. (2012) Accidental Deaths and Suicides in India. In: Affairs MoH (ed). New Delhi: Government of India.

NCRB. (2014) Accidental Deaths and Suicides in India. In: Affairs MoH (ed). New Delhi: Government of India.

Patel V. (2005) Poverty, gender and mental health promotion in a global society. Promotion \& Education 12: 26-29.

Patel V. (2007) Alcohol use and mental health in developing countries. Annals of Epidemiology 17: S87-S92.

Patel V, Ramasundarahettige C, Vijayakumar L, et al. (2012) Suicide mortality in India: a nationally representative survey. The Lancet 379: 2343-2351.

Patton MQ. (1990) Qualitative evaluation and research methods: Sage Publications. 
Radhakrishnan R and Andrade C. (2012) Suicide: An Indian perspective. Indian journal of psychiatry 54: 304-319.

Rao AV. (1978) Some Aspects of Psychiatry in India. Transcultural Psychiatry 15: 7-27.

Saunders KE and Hawton K. (2006) Suicidal behaviour and the menstrual cycle. Psychological Medicine 36: 901-912.

Skeggs B. (1997) Formations of class and gender : becoming respectable, London: SAGE.

Spivak GC. (1988) Can the subaltern speak?, Basingstoke: Macmillan.

Staples J. (2012a) Introduction: Suicide in South Asia: Ethnographic perspectives. Contributions to Indian Sociology 46: 1-28.

Staples J. (2012b) The suicide niche: Accounting for self-harm in a South Indian leprosy colony. Contributions to Indian Sociology 46: 117-144.

Tasto DL and Insel PM. (2013) The Premenstrual and Menstrual Syndromes - A Psychological Approach. In: Rachman S (ed) Contributions to medical psychology. London: Elsevier.

Vijayakumar L. (2007) Suicide and its prevention: The urgent need in India. . Indian J Psychiatry 49: 81-84.

Vijayakumar L, Nagaraj K, Pirkis J, et al. (2005) Suicide in developing countries (1) - Frequency, distribution, and association with socioeconomic indicators. Crisis-the Journal of Crisis Intervention and Suicide Prevention 26: 104-111.

Vijaykumar L. (2007) Suicide and its prevention: The urgent need in India. . Indian J Psychiatry 49: 81-84. 